\title{
Manual evaluation of the diaphragm muscle
}

This article was published in the following Dove Press journal:

International Journal of COPD

18 August 2016

Number of times this article has been viewed

\author{
Bruno Bordoni ${ }^{1-3}$ \\ F Marelli ${ }^{2,3}$ \\ B Morabito ${ }^{2-4}$ \\ B Sacconi ${ }^{5}$ \\ 'Department of Cardiology, \\ Foundation Don Carlo Gnocchi \\ IRCCS, Institute of Hospitalization \\ and Care with Scientific Address, \\ Milan, ${ }^{2}$ CRESO, School of Osteopathic \\ Centre for Research and Studies, \\ Castellanza, ${ }^{3}$ CRESO, School of \\ Osteopathic Centre for Research \\ and Studies, Falconara Marittima, \\ ${ }^{4}$ Foundation Polyclinic University \\ A Gemelli, University Cattolica \\ del Sacro Cuore, ${ }^{5}$ Radiological, \\ Oncological and Anatomopathological \\ Sciences, Sapienza University of Rome, \\ Rome, Italy
}

Correspondence: Bruno Bordoni Department of Cardiology, Foundation Don Carlo Gnocchi IRCCS, Institute of Hospitalization and Care with Scientific Address, S Maria Nascente, Via Capecelatro 66, Milan 20100, Italy Tel +3923496300617 Email bordonibruno@hotmail.com
Abstract: The respiratory diaphragm is the most important muscle for breathing. It contributes to various processes such as expectoration, vomiting, swallowing, urination, and defecation. It facilitates the venous and lymphatic return and helps viscera located above and below the diaphragm to work properly. Its activity is fundamental in the maintenance of posture and body position changes. It can affect the pain perception and emotional state. Many authors reported on diaphragmatic training by using special instruments, whereas only a few studies focused on manual therapy approaches. To the knowledge of the authors, the existing scientific literature does not exhaustively examines the manual evaluation of the diaphragm in its different portions. A complete evaluation of the diaphragm is mandatory for several professional subjects, such as physiotherapists, osteopaths, and chiropractors not only to elaborate a treatment strategy but also to obtain information on the validity of the training performed on the patient. This article aims to describe a strategy of manual evaluation of the diaphragm, with particular attention to anatomical fundamentals, in order to stimulate further research on this less explored field.

Keywords: diaphragm, osteopathic evaluation, manual therapy, chiropractic, physiotherapy

\section{Introduction}

Breathing is a systemic act, involving the whole body, the viscera, the nervous system, and emotions. The diaphragm muscle is the main breathing muscle, influencing with its contractions the respiratory activity. ${ }^{1}$ The diaphragm collaborates to various processes such as expectoration, vomiting, swallowing, urination, and defecation. ${ }^{1}$ It facilitates the venous and lymphatic return and helps the viscera above and below the diaphragm to work properly. ${ }^{1}$ Diaphragm's activity is fundamental in the maintenance of posture and body position changes and influences the pain perception, usually decreased during the inspiratory apnoea. ${ }^{1,2}$ Diaphragmatic movements also change the body pressure, as it facilitates the venous and lymphatic return. ${ }^{2}$ This pressure modulation influences the blood redistribution, which could be probably correlated with the response of baroreceptors and the reduction of pain perception, although there are not scientific studies supporting this hypothesis yet. ${ }^{2}$

The most important stimulus for the respiratory acts is provided by chemoreceptors, whose task is to maintain the biochemical balance of the body. ${ }^{2}$ Breathing is also influenced by internal and external conditions, with other ways of neural stimulation beyond the chemoreceptorial stimulation. ${ }^{2}$ The diaphragmatic activity is not only controlled by metabolic mechanism but also by emotional states such as sadness, fear, anxiety, and anger. ${ }^{2}$ Breathing stimulates mechanoreceptors of the diaphragm and the visceroceptors of viscera (moving during the respiratory acts), constituting the mechanism of interoception. ${ }^{2}$ Interoception is the awareness of the body condition obtained from information coming directly from the body itself. ${ }^{2}$ Diaphragmatic movements also stimulate the skin and the mediastinum; this complex of afferent information 
determines the central representation of breathing. ${ }^{2}$ The amygdala, which is part of the limbic system, is reciprocally connected to each of the respiratory areas, just as the medulla oblongata, and is considered the most important area that manages emotive breathing. ${ }^{2}$ A respiratory disorder certainly alters the emotional framework, such as depression and anxiety, as well as the emotional state can negatively affect the respiratory activity. ${ }^{2}$

In case of systemic disease, the diaphragm is always involved, negatively contributing to the set of symptoms. In chronic heart failure, the diaphragm is weaker, more commonly placed in expiratory state, with more frequent movements. ${ }^{3,4}$

The pathological changes are seen in patients with chronic obstructive pulmonary disease (COPD). ${ }^{5}$

The progressive limitation of the airflow in COPD patients causes a pathological adaptation of the diaphragm, although the reasons for these changes are not fully clear. These changes in position adversely affect the exercise tolerance; more in detail, the dome of the diaphragm is lowered, in inspiratory position. ${ }^{6}$ The contractile force is decreased, with electrical and metabolic alterations. The muscle thickness is increased, especially on the left side, with decreased mechanical excursion, probably due to fibers' shortening. ${ }^{7,8}$ A decrease of anaerobic type fibers (type II) and an increase in aerobic fibers (type I) are observed; this process progressively increases with the pathology worsening. ${ }^{8}$ The increase in the oxidative process, however, does not correspond to an improvement of the diaphragmatic function. The rate of detectable myosin decreases, resulting in altered sarcomeric organization and further decreasing of the contractile strength. ${ }^{8}$ The phrenic activity is abnormal, presumably due to the nerve stretching caused by the chronic lowering of the diaphragm, resulting in such a neuropathy. ${ }^{9}$ The exercise intolerance in patients with congestive heart failure and COPD does not correlate with the common functional indexes (ejection frequency and forced expiratory volume in 1 second); rather it is the peripheral muscle adaptation, including that of the diaphragm, to have a heavy influence on the symptomatic scenario..$^{10,11}$

As mentioned in the article, the diaphragm influences the patient's emotional state. In patients with COPD, the incidence of depression varies from $8 \%$ to $80 \%$, according to different studies. ${ }^{12}$ Depression may be considered a predictor of mortality during hospitalization for acute respiratory events. ${ }^{13}$ Depression and anxiety negatively affect the rehospitalization, but only $33 \%$ of patients are treated with a pharmacological process taking into account these psychiatric symptoms. ${ }^{13}$ Depression affects the physical status of the patient, as demonstrated by some authors who observed a worsening in the test of Cooper (12 minutes run) and an increased mortality rate. ${ }^{13}$ Anyway, there are not enough data exhaustively explaining this correlation. ${ }^{13}$ The copresence of depression and anxiety in patients with COPD increases the mortality rate (of $83 \%$ according to some authors). ${ }^{14,15}$ The incidence of depression/anxiety increases with COPD worsening. ${ }^{12,15}$ Even in this case, the exact mechanisms leading to this correlation are unclear; probably the presence of dyspnea, systemic inflammation, and the effects on the brain system derived from the smoking cessation are involved. ${ }^{12}$ Anyway, improving respiratory function improves psychiatric symptoms, with exercise and manual therapy. ${ }^{12,16}$

To the knowledge of the authors, the existing scientific literature does not exhaustively examines the manual evaluation of the diaphragm in its different portions. A complete evaluation of the diaphragm is mandatory for several professional subjects, such as physiotherapists, osteopaths, and chiropractors not only to elaborate a treatment strategy but also to obtain information on the validity of the training performed on the patient. This article aims to describe a hypothesis of manual evaluation of the diaphragm, with particular attention to anatomical fundamentals, in order to stimulate further research on this less explored field.

\section{Anatomy of the diaphragm: origin and insertion}

An accurate knowledge of the anatomy of diaphragm is necessary in order to perform a proper manual evaluation of the muscle, with particular focus on hands' positioning.

According to its insertions, the diaphragm can be divided in costal, lumbar, and sternal portions. The sternal part arises with two small fiber bundles from the posterior aspect of the xiphoid process, near to the apex; the costal (or lateral) portion arises from the inner and superior aspect of the last six ribs, with interdigitation with the transverse muscle of the abdomen. ${ }^{17}$ The lumbar portions arises from the medial, intermediate, and lateral ligaments of the diaphragm. The medial ligaments, before reaching the vertebral bodies, delimitate with their internal muscular bundles, at the level of D11, the esophageal hiatus for the passage of the esophagus and vagus nerves. The right medial ligament, thicker and longer than the left one, terminates in a flattened tendon on the anterior aspect of L2-L3 (sometimes up to L4). ${ }^{17}$ Laterally to the right ligament, there is a small ligament (called accessory or intermediate), whose tendon is inserted at the level of L1-L2. Between this ligament and the right medial one, there is a vertical split crossed by 
the large splanchnic nerve and the medial root of the azygos vein. ${ }^{17}$ The left medial ligament ends with a flattened tendon between L2 and L3; even in this case an accessory ligament is present, forming a split for the large splanchnic nerve and the medial root of hemiazygos vein. ${ }^{17}$ The tendons of these two ligaments constitute, at the level of D12, a tendinous arch (called the median arcuate ligament), through which the aorta and the thoracic duct cross the diaphragm. ${ }^{17}$ The lateral ligaments arise in the form of two thick tendons at the level of the arch of the psoas muscle, constituting the medial arcuate ligament; the latter passes above the psoas muscle, joining the vertebral body of L1 and its transverse apophyses, and more laterally, above the quadrates lumborum muscle, joining the transverse process of $\mathrm{L} 1$ and the apex of the $12^{\circ} \mathrm{rib}$, forming the lateral arcuate ligament. ${ }^{17}$

The respiratory diaphragm muscle is innervated by the phrenic nerve (C3-C5) and the vagus nerve (cranial nerve X); the first receives pulses from groups of medullary neurons of the pre-Bötzinger complex and from neurons of the parafacial retrotrapezoid complex (correlated in turn with the retroambiguus nucleus of the medulla); however, it is worth to mention that these connections are still unclear. ${ }^{17}$ The vagus nerve is part of the parasympathetic autonomic system, originating from the ambiguus nucleus of the medulla. ${ }^{17}$

The normal position of the diaphragm can be seen in the chest X-ray. On the anterior-posterior projection, the dome of the right hemidiaphragm is located at the level of $5^{\circ}-6^{\circ}$ rib for what regard the anterior part, whereas the posterior one usually lies at the level of the $10^{\circ}$ rib. ${ }^{18}$ The left hemidiaphragm is slightly higher (about one intercostal space). ${ }^{13}$ In $10 \%$ of people, both domes have the same height, becoming difficult to be differentiated in the lateral projection. ${ }^{18}$ Computed tomography and magnetic resonance imaging are also useful in the morphological evaluation of the diaphragm, even though they are used in second analysis, due to their costs and availability. ${ }^{18}$ Fluoroscopy and ultrasounds are techniques employed for the real-time evaluation of the moving diaphragm, even though affected by visibility limitations. ${ }^{18}$ In most cases, the diaphragm shows a symmetrical respiratory excursion of $\sim 2-10 \mathrm{~cm}$, not related to the vital capacity of the lungs. ${ }^{18}$ The ribs open out laterally in caudal direction during inspiration, and the opposite during expiration. ${ }^{1}$ By aging, the diaphragm becomes thinner and more frequently located in expiratory position, especially in males. ${ }^{19}$

\section{Physiotherapy and diaphragm}

In literature, there are many physiotherapeutic approaches based on diaphragm's adaptability. The resistance training in anaerobic regimen, or other training programs in aerobic regimen, with different devices, can be used with increased diaphragm performance in patients affected by respiratory diseases..$^{20,21}$

The respiratory rehabilitation improves the diaphragmatic motion in both sides (using fluoroscopy imaging) in COPD patients and improves the performance, structural, and metabolic characteristics of the respiratory muscle (muscle strength [PI $\left.\{\max \}, \mathrm{cm} \mathrm{H}_{2} \mathrm{O}\right]$ ), endurance (inspiratory threshold loading, $\mathrm{kPa}$ ), exercise capacity (Borg scale for respiratory effort, modified Borg scale, work rate maximum, W), dyspnea (transition dyspnea index). ${ }^{20-22}$

Several tools such as bikes or cycle ergometers for the upper limbs, or breathing stimulators (with different resistances to be overcome during the inspiration), are usually employed. ${ }^{23}$ Diaphragm training (with the aim to improve lung capacity) is also used in other pathologic scenarios, such as in patients who have undergone sternotomy for cardiac surgery, and in patients affected by stroke. ${ }^{24,25}$ Diaphragm training also improves other symptoms, such as those cause by gastroesophageal reflux, and improves muscle proprioception of the lumbar-sacral region. ${ }^{26,27}$

Currently, the literature shows that there are no significant differences in the rehabilitation results of the physical therapy in patients with COPD, in terms of comparison between the use of endurance and resistance training. ${ }^{28-30}$

\section{Manual therapy and diaphragm}

A few studies examined the manual evaluation of the diaphragm; although a review of the literature was not among the aims of this paper, some short texts on the topic need to be mentioned.

Potential therapeutic approaches involving the diaphragm muscle have been proposed among gentle myofascial release techniques, in the context of the therapeutic techniques addressed to other diaphragms of the human body. 3,31 The myofascial technique is the application of a low load, long duration, stretch into the myofascial complex, with the aim to restore the optimal length of this complex. ${ }^{32}$ The operator palpates the fascial restriction and the pressure is applied directly to the skin, into the direction of the restriction, until resistance (the tissue barrier) is manually perceived. ${ }^{32}$ Once found, the collagenous barrier is engaged for a few minutes, without sliding over the skin or forcing the tissue, until the band starts to yield the complex and a sensation of softening is achieved. ${ }^{32}$

Other types of manual (osteopathic) techniques employ myofascial approaches, in particular by placing the hands 
under the chondrocostal junctions, inducing and facilitating respiratory acts. ${ }^{33,34}$ The same techniques are also used in other fields, such as to improve the symptoms of gastroesophageal reflux, and to alleviate somatic symptoms in pregnant women. ${ }^{35,36}$

There are several studies evaluating the effects of the manual therapy in COPD. The approach to the patient varies widely, both in terms of techniques and time management: thoracic spinal mobilization, lymphatic drainage or pump, diaphragmatic release trigger points, massage, articulation techniques for ribs, myofascial release to the thoracic outlet, suboccipital decompression, and muscular stretching. ${ }^{16,37,38}$ The results of the various respiratory parameters are always positive, but we have not enough information to draw definitive conclusions.

Only recently, physiotherapy and manual therapy have been used together in the treatment of patients with COPD. A previous study aims to assess the effect of these two therapeutic strategies, showing that the combination of rehabilitation and osteopathy led to better results in comparison with the single approach (increase in forced expiratory volume in 1 second, 6-minute walk test, decrease in residual volume). ${ }^{39}$

A recent study on COPD patients shows that many parameters (mobility, exercise capacity, maximal respiratory pressure, and vital capacity) are improved by working the anterior chondrocostal arch with manual diaphragm release technique. $^{40}$

We need to find the correct technique to manually evaluate the diaphragm, in order to improve the complementary use of the usual rehabilitation and manual therapy.

\section{Proposal of a manual evaluation technique for the diaphragm muscle}

The technique for the manual evaluation of the diaphragm proposed in the present article arises from the growing need to combine physiotherapy with manual therapy, considering the new clinical data.

It is well known that, in patients with COPD or congestive heart failure, the diaphragm has a specific preferred position, which can be measured with different clinical tools. According to a recent study, human touch can distinguish any slight variation, measurable in microns. ${ }^{41}$

We can strongly speculate on the possibility to train the therapist, in terms of palpation technique, to check the mobility and function of the inspiratory muscle, in order to obtain additional clinical information on the therapeutic approach, before and after the physiotherapy (as usually happens for doctors in osteopathy). ${ }^{42}$
This manual evaluation is based on the experience of authors, consisting in $>20$ years of clinical practice with patients affected by respiratory and cardiac diseases; the proposed method for COPD patients obviously need to be deepened with further studies. It is important to remember that, as for many other therapeutic techniques, whether manual or otherwise, scientific proof is not available for every existing treatment, this does not mean that, in absence of scientific evidence, something is not valid; otherwise there would not be new treatments or any improvement in rehabilitative practice. ${ }^{31}$ In this regard, we wish to recall that the evidence-based medicine, originated in the second half of the 19th century, is based on the individual clinical expertise, best external evidence, patient values, and expectations:

External clinical evidence can inform, but can never replace, individual clinical expertise, and it is this expertise that decides whether the external evidence applies to the individual patient at all and, if so, how it should be integrated into a clinical decision. ${ }^{43}$

There are no previous papers dealing with a comprehensive evaluation of the diaphragm through manual approach, and a description of techniques to be performed to evaluate this muscle in all its portions is currently missing. We do not have complete data on what happens in the different anatomical areas of the diaphragm in patients with respiratory disease; this text could be used as a guideline for researchers for further evaluation.

The patient is supine, in comfortable position. The first step deals with the assessment of the costal movement; this should consist of lateralization during inspiration, with a caudal direction, and the opposite during expiration. ${ }^{44}$ In case of dysfunction of the diaphragm, this costal movement is usually limited. ${ }^{45}$ The hands must be gently hold on the lateral sides of the costal margins, in order to have a palpatory feedback of the costal behavior during breathing (Figure 1).

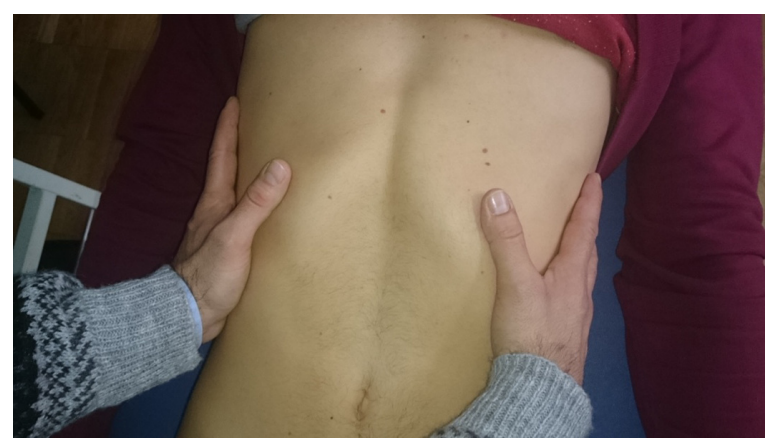

Figure I The hands must be gently placed on the lateral sides of the costal margins to receive palpation feedback of the costal behavior during breathing. 


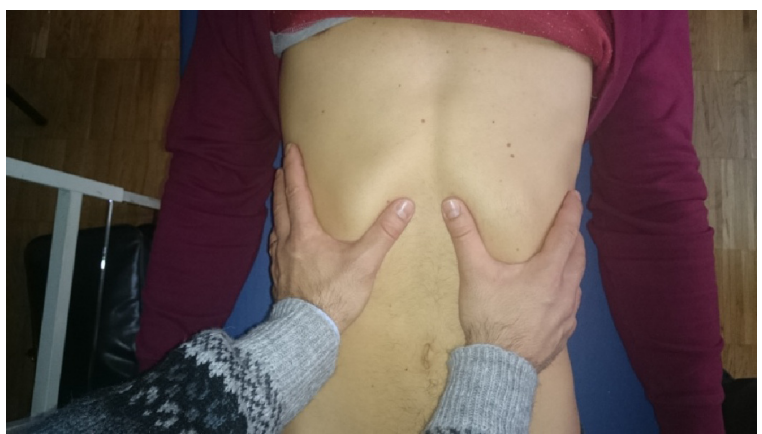

Figure 2 The hands can be held anteriorly on the costal margins, with the thumbs being at the level of the margins and the other fingers placed across the upper ribs. This manual position can be used to assess the diaphragmatic excursion.

In the following evaluation, respecting the previously described anatomy, the hands can be hold on the costal margins, anteriorly, with the thumbs being at the margin's level and the other fingers lying on the upper ribs. Since the diaphragm muscle is lowered during inspiration, and then rises during expiration, this manual position can be used to assess the diaphragmatic excursion (Figure 2). ${ }^{1,17}$

The following manual positions deal with the evaluation of the various portions of the diaphragm: domes, posterolateral area, xyphocostal area, medial ligament, and lateral ligament.

To evaluate the diaphragmatic domes, the operator's forearm has to be hold parallel to the abdomen of the patient, with the thenar and hypothenar eminences of the hand at the level of the anterior margin of the costal arch; a gentle push must be performed in cranial direction, so as to record the elastic response of the tissue, for the right side as well as for the left one (Figure 3). As usually observed in manual tests, the elasticity of the tissue is reduced when a reduced movement is obtained in response to the applied stimulus. ${ }^{42}$

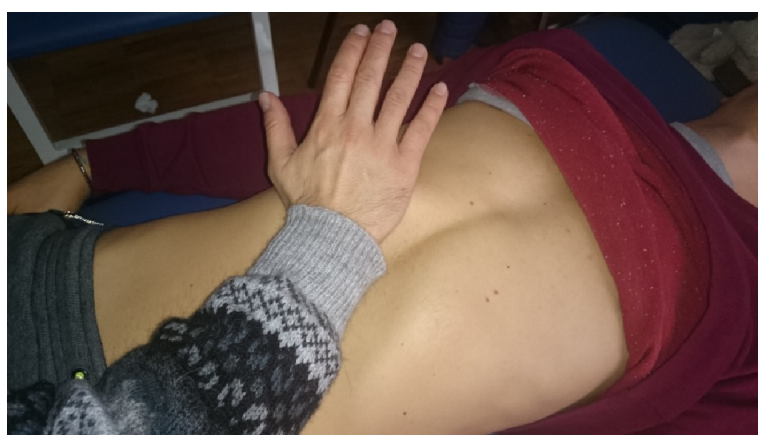

Figure 3 To evaluate the diaphragmatic domes, the operator's forearm has to be held parallel to the abdomen of the patient, with the thenar and hypothenar eminences of the hand at the level of the anterior margin of the costal arch; a gentle push must be performed in the cranial direction, so as to record the elastic response of the tissue, for both right and let sides.

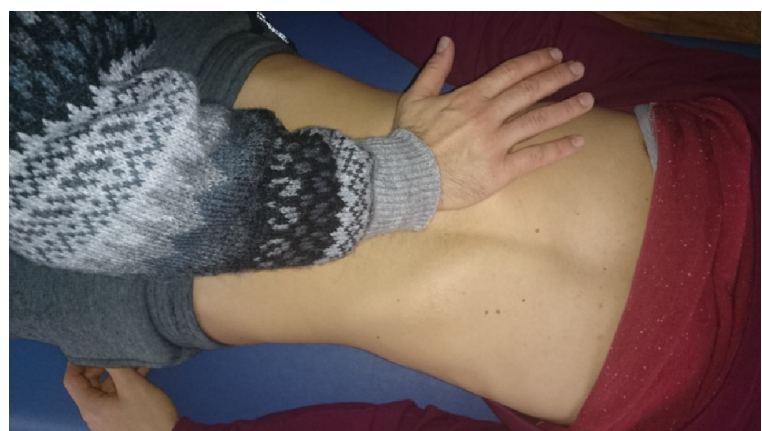

Figure 4 To evaluate the posterolateral area, the hand must be held as previously described for the domes, but with the forearm forming a $45^{\circ}$ angle with the patient's abdomen; a gentle push must be applied obliquely, following the line of the same forearm.

To evaluate the posterolateral area, the hand must be hold as previously described for the domes, but with the forearm forming an angle of $45^{\circ}$ with the patient's abdomen; a gentle push must be applied obliquely, following the line of the same forearm (Figure 4). This step needs to be repeated for the other side also. This portion of the diaphragm shows higher movement excursion during the respiration and has a more vertical inclination in comparison with the domes. ${ }^{18}$

The evaluation of the xyphoid-costal area is used to assess whether, during inspiration and expiration, there is regular elasticity of the tissue, which is necessary for normal breathing; in fact, this area is usually more rigid in case of abnormal diaphragmatic activity. ${ }^{45}$ The hand and the forearm are positioned as in the evaluation of the domes, but in the xyphoid area; a gentle push must be applied cranially (Figure 5).

For medial ligaments, the spinal elasticity needs to be evaluated, with the patient being supine. The operator hold the last phalanges of the fingers (of one or both hands) placed

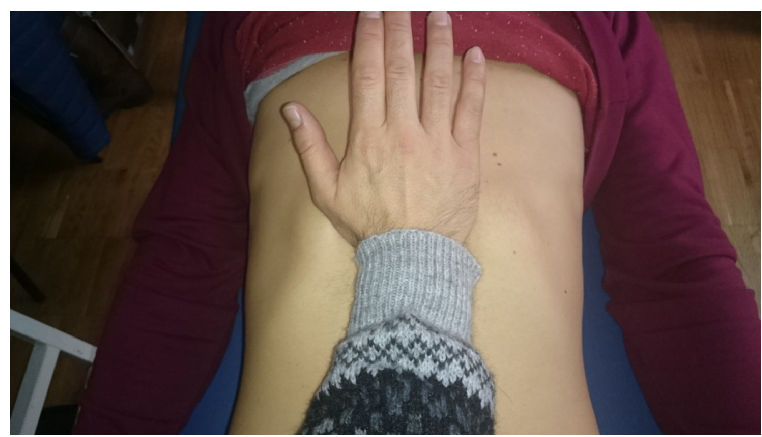

Figure 5 The evaluation of the xyphoid-costal area is used to assess whether there is regular elasticity of the tissue during inspiration and expiration, which is necessary for normal breathing. The hand and the forearm are positioned as in the evaluation of the domes, but in the xyphoid area; a gentle push must be applied cranially. 


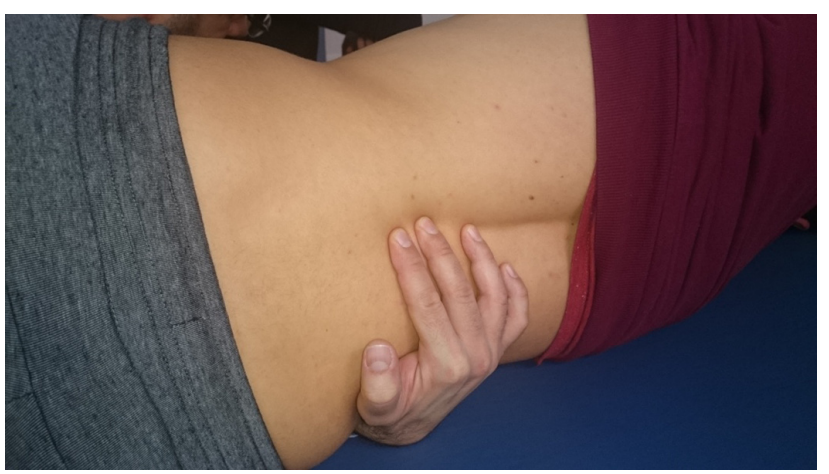

Figure 6 For medial ligaments, the spinal elasticity needs to be evaluated, with the patient being supine. The operator should hold the last phalanges of the fingers (of one or both hands) placed in the interspinous spaces of DII and DI2; by using a gentle push towards the ceiling, a passive extension of the vertebra is obtained, in order to deduce information on their elasticity.

in the interspinous spaces of D11 and D12; by using a gentle push toward the ceiling, a passive extension of the vertebra is obtained, in order to deduce information on its elasticity (Figure 6). ${ }^{42}$ The same technique is used to evaluate the lumbar vertebral bodies up to L4. ${ }^{42}$ The medial ligaments play an important role in the mechanics of the dorsolumbar region, in synergy with the abdominal wall muscles and the thoracolumbar fascia. ${ }^{1,17,46}$

The lateral ligaments are evaluated by actively soliciting the last rib. On the opposite side compared to the rib to be evaluated, the body of the rib must be hold with one hand, and a gentle traction must be performed toward the operator (Figure 7). The lateral ligaments play an important role in managing the tension affecting the diaphragm and the thoracolumbar fascia. ${ }^{17,46}$

The main purpose of using such manual evaluation is to understand whether there is a restriction of movement in a specific area of the diaphragm muscle, in order to plan a manual treatment focused on the dysfunctional area,

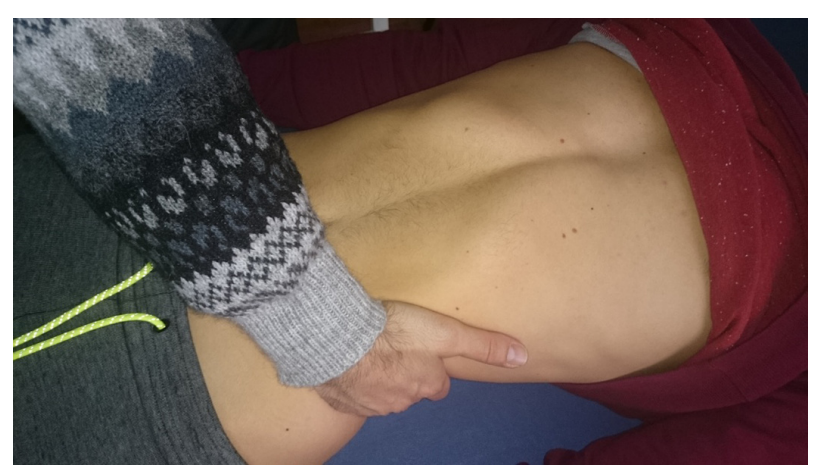

Figure 7 The lateral ligaments are evaluated by actively involving the last rib. On the opposite side of the rib to be evaluated, the body of the rib must be held with one hand, and a gentle traction must be performed toward the operator.

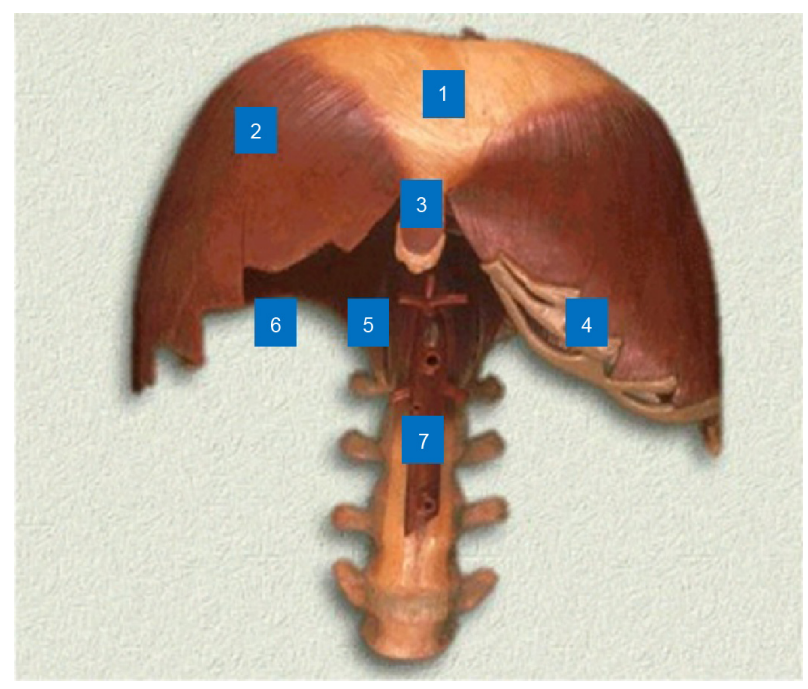

Figure 8 Anatomical model.

Notes: (1) center tendon, (2) anterior diaphragmatic dome, (3) xiphoid area, (4) costal area, (5) medial ligaments, (6) lateral ligaments, and (7) aorta.

combining the manual approach to the usual rehabilitation process (Figure 8). The combination of several techniques in a multidisciplinary process can be of benefit for the improvement of the respiratory performance. ${ }^{47,48}$

We hope that this article could contribute to the state of the art, representing a starting point, and enhancing the need for further research in this field.

\section{Conclusion}

The breath is a systemic activity, able to involve several body parts. The health of the diaphragm muscle is critical for many patients, not just those with respiratory diseases. A proper training of the main respiratory muscle can be of benefit in several clinical scenarios; however, there are not so many authors reporting on therapeutic techniques focused on manual approaches and, more in detail, on the manual evaluation of the diaphragm. This article aims to describe a hypothesis of manual evaluation of the diaphragm, with particular attention to anatomical fundamentals. The technique for the manual evaluation of the diaphragm proposed in the present article arises from the increasing need to combine physiotherapy with manual therapy, considering the new clinical data. We do not have complete knowledge on what happens in the different anatomical areas of the diaphragm in patients with respiratory disease; this text could be used as a guideline for researchers for further evaluation.

\section{Disclosure}

The authors report no conflicts of interest in this work. 


\section{References}

1. Bordoni B, Marelli F. Failed back surgery syndrome: review and new hypotheses. J Pain Res. 2016;9:17-22.

2. Bordoni B, Marelli F, Bordoni G. A review of analgesic and emotive breathing: a multidisciplinary approach. J Multidiscip Healthc. 2016;9: 97-102.

3. Bordoni B, Marelli F. The fascial system and exercise intolerance in patients with chronic heart failure: hypothesis of osteopathic treatment J Multidiscip Healthc. 2015;8:489-494.

4. Caruana L, Petrie MC, McMurray JJ, MacFarlane NG. Altered diaphragm position and function in patients with chronic heart failure Eur J Heart Fail. 2001;3(2):183-187.

5. Salito C, Luoni E, Aliverti A. Alterations of diaphragm and rib cage morphometry in severe COPD patients by CT analysis. Conf Proc IEEE Eng Med Biol Soc. 2015;2015:6390-6393.

6. Hellebrandová L, Chlumský J, Vostatek P, Novák D, Rýznarová Z, Bunc V. Airflow limitation is accompanied by diaphragm dysfunction. Physiol Res. Epub 2016 Apr 12.

7. Baria MR, Shahgholi L, Sorenson EJ, et al. B-mode ultrasound assessment of diaphragm structure and function in patients with COPD. Chest. 2014;146(3):680-685.

8. Ottenheijm CA, Heunks LM, Dekhuijzen PN. Diaphragm muscle fiber dysfunction in chronic obstructive pulmonary disease: toward a pathophysiological concept. Am J Respir Crit Care Med. 2007;175(12): 1233-1240.

9. El-Tantawi GA, Imam MH, Morsi TS. Phrenic nerve conduction abnormalities correlate with diaphragmatic descent in chronic obstructive pulmonary disease. COPD. 2015;12(5):516-524.

10. Vogiatzis I, Zakynthinos S. The physiological basis of rehabilitation in chronic heart and lung disease. J Appl Physiol (1985). 2013;115(1): 16-21.

11. Evans RA, Singh SJ, Collier R, Loke I, Steiner MC, Morgan MD. Generic, symptom based, exercise rehabilitation; integrating patients with COPD and heart failure. Respir Med. 2010;104(10):1473-1481.

12. Smith MC, Wrobel JP. Epidemiology and clinical impact of major comorbidities in patients with COPD. Int J Chron Obstruct Pulmon Dis. 2014;9:871-888.

13. Pooler A, Beech R. Examining the relationship between anxiety and depression and exacerbations of COPD which result in hospital admission: a systematic review. Int J Chron Obstruct Pulmon Dis. 2014; 9:315-330

14. Smith SM, Sonego S, Ketcheson L, Larson JL. A review of the effectiveness of psychological interventions used for anxiety and depression in chronic obstructive pulmonary disease. BMJ Open Respir Res. 2014;1(1): e000042.

15. Atlantis E, Fahey P, Cochrane B, Smith S. Bidirectional associations between clinically relevant depression or anxiety and COPD: a systematic review and meta-analysis. Chest. 2013;144(3):766-777.

16. Wearing J, Beaumont S, Forbes D, Brown B, Engel R. The use of spinal manipulative therapy in the management of chronic obstructive pulmonary disease: a systematic review. J Altern Complement Med. 2016; 22(2):108-114.

17. Bordoni B, Zanier E. Anatomic connections of the diaphragm: influence of respiration on the body system. J Multidiscip Healthc. 2013;6: 281-291.

18. Roberts HC. Imaging the diaphragm. Thorac Surg Clin. 2009;19(4): 431-450.

19. Suwatanapongched T, Gierada DS, Slone RM, Pilgram TK, Tuteur PG. Variation in diaphragm position and shape in adults with normal pulmonary function. Chest. 2003;123(6):2019-2027.

20. Chun EM, Han SJ, Modi HN. Analysis of diaphragmatic movement before and after pulmonary rehabilitation using fluoroscopy imaging in patients with COPD. Int J Chron Obstruct Pulmon Dis. 2015;10: 193-199.

21. Mills DE, Johnson MA, Barnett YA, Smith WH, Sharpe GR. The effects of inspiratory muscle training in older adults. Med Sci Sports Exerc. 2015; 47(4):691-697.
22. Geddes EL, Reid WD, Crowe J, O'Brien K, Brooks D. Inspiratory muscle training in adults with chronic obstructive pulmonary disease: a systematic review. Respir Med. 2005;99(11):1440-1458.

23. Geddes EL, O’Brien K, Reid WD, Brooks D, Crowe J. Inspiratory muscle training in adults with chronic obstructive pulmonary disease: an update of a systematic review. Respir Med. 2008;102(12):1715-1729.

24. Kodric M, Trevisan R, Torregiani C, et al. Inspiratory muscle training for diaphragm dysfunction after cardiac surgery. J Thorac Cardiovasc Surg. 2013;145(3):819-823.

25. Jung JH, Kim NS. The effect of progressive high-intensity inspiratory muscle training and fixed high-intensity inspiratory muscle training on the asymmetry of diaphragm thickness in stroke patients. JPhys Ther Sci. 2015;27(10):3267-3269.

26. Nobre e Souza MÂ, Lima MJ, Martins GB, et al. Inspiratory muscle training improves antireflux barrier in GERD patients. Am J Physiol Gastrointest Liver Physiol. 2013;305(11):G862-G867.

27. Janssens L, McConnell AK, Pijnenburg M, et al. Inspiratory muscle training affects proprioceptive use and low back pain. Med Sci Sports Exerc. 2015;47(1):12-19.

28. Iepsen UW, Jørgensen KJ, Ringbaek T, Hansen H, Skrubbeltrang C, Lange P. A systematic review of resistance training versus endurance training in COPD. J Cardiopulm Rehabil Prev. 2015;35(3):163-172.

29. Alison JA, McKeough ZJ. Pulmonary rehabilitation for COPD: are programs with minimal exercise equipment effective? J Thorac Dis. 2014; 6(11):1606-1614.

30. Emtner M, Wadell K. Effects of exercise training in patients with chronic obstructive pulmonary disease - a narrative review for FYSS (Swedish Physical Activity Exercise Prescription Book). Br J Sports Med. 2016; 50(6):368-371.

31. Bordoni B, Zanier E. The continuity of the body: hypothesis of treatment of the five diaphragms. J Altern Complement Med. 2015; 21(4):237-242.

32. Bordoni B, Zanier E. Understanding fibroblasts in order to comprehend the osteopathic treatment of the fascia. Evid Based Complement Alternat Med. 2015;2015:860934.

33. Yao S, Hassani J, Gagne M, George G, Gilliar W. Osteopathic manipulative treatment as a useful adjunctive tool for pneumonia. $J$ Vis Exp. 2014;87:e50687.

34. Valenza MC, Cabrera-Martos I, Torres-Sánchez I, Garcés-García A, Mateos-Toset S, Valenza-Demet G. The effects of doming of the diaphragm in subjects with short-hamstring syndrome: a randomized controlled trial. J Sport Rehabil. 2015;24(4):342-348.

35. Diniz LR, Nesi J, Curi AC, Martins W. Qualitative evaluation of osteopathic manipulative therapy in a patient with gastroesophageal reflux disease: a brief report. J Am Osteopath Assoc. 2014;114(3): 180-188.

36. Lavelle JM. Osteopathic manipulative treatment in pregnant women. J Am Osteopath Assoc. 2012;112(6):343-346.

37. Noll DR, Johnson JC, Baer RW, Snider EJ. The immediate effect of individual manipulation techniques on pulmonary function measures in persons with chronic obstructive pulmonary disease. Osteopath Med Prim Care. 2009;3:9.

38. Heneghan NR, Adab P, Balanos GM, Jordan RE. Manual therapy for chronic obstructive airways disease: a systematic review of current evidence. Man Ther. 2012;17(6):507-518.

39. Zanotti E, Berardinelli P, Bizzarri C, et al. Osteopathic manipulative treatment effectiveness in severe chronic obstructive pulmonary disease: a pilot study. Complement Ther Med. 2012;20(1-2):16-22.

40. Rocha T, Souza H, Brandão DC, et al. The manual diaphragm release technique improves diaphragmatic mobility, inspiratory capacity and exercise capacity in people with chronic obstructive pulmonary disease: a randomised trial. J Physiother. 2015;61(4):182-189.

41. Bordoni B, Zanier E. Sutherland's legacy in the new millennium: the osteopathic cranial model and modern osteopathy. Adv Mind Body Med. 2015;29(2):15-21.

42. Chila AG. Foundations for Osteopathic Medicine. 3rd ed. Philadelphia, PA: Lippincott Williams \& Wilkins; 2010. 
43. Masic I, Miokovic M, Muhamedagic B. Evidence based medicine-new approaches and challenges. Acta Inform Med. 2008;16(4):219-225.

44. Vostatek P, Novák D, Rychnovský T, Rychnovská S. Diaphragm postural function analysis using magnetic resonance imaging. PLoS One. 2013;8(3):e56724.

45. Chaitow L, Bradley D, Gilbert C. Recognizing and Treating Breathing Disorders. A Multidisciplinary Approach. 2nd ed. London: Churchill Livingstone; 2013.

46. Vleeming A, Schuenke MD, Danneels L, Willard FH. The functional coupling of the deep abdominal and paraspinal muscles: the effects of simulated paraspinal muscle contraction on force transfer to the middle and posterior layer of the thoracolumbar fascia. J Anat. 2014; 225(4):447-462.
47. Engel RM, Vemulpad SR, Beath K. Short-term effects of a course of manual therapy and exercise in people with moderate chronic obstructive pulmonary disease: a preliminary clinical trial. $J$ Manipulative Physiol Ther. 2013;36(8):490-496.

48. Engel R, Vemulpad S. The role of spinal manipulation, soft-tissue therapy, and exercise in chronic obstructive pulmonary disease: a review of the literature and proposal of an anatomical explanation. J Altern Complement Med. 2011;17(9):797-801.

\section{Publish your work in this journal}

The International Journal of COPD is an international, peer-reviewed journal of therapeutics and pharmacology focusing on concise rapid reporting of clinical studies and reviews in COPD. Special focus is given to the pathophysiological processes underlying the disease, intervention programs, patient focused education, and self management protocols.

\section{Dovepress}

This journal is indexed on PubMed Central, MedLine and CAS. The manuscript management system is completely online and includes a very quick and fair peer-review system, which is all easy to use. Visit http://www.dovepress.com/testimonials.php to read real quotes from published authors.

Submit your manuscript here: http://www.dovepress.com/international-journal-of-chronic-obstructive-pulmonary-disease-journal 